\title{
Addressing legal and policy barriers to male circumcision for adolescent boys in South Africa
}

\author{
A E Strode, ${ }^{1,2}$ LLM, PhD; J D Toohey, ${ }^{2}$ LLB; C M Slack, ${ }^{2}$ MA Clin Psyc, PhD \\ ${ }^{1}$ School of Law, University of KwaZulu-Natal and member of the HIV/AIDS Vaccines Ethics Group, School of Applied Human Sciences, University \\ of KwaZulu-Natal, Pietermaritzburg, South Africa \\ ${ }^{2}$ HIV/AIDS Vaccines Ethics Group, School of Applied Human Sciences, College of Humanities, University of KwaZulu-Natal, Pietermaritzburg, \\ South Africa
}

Corresponding author: A Strode (strodeA@ukzn.ac.za)

With millions of adolescents becoming infected with HIV globally, it is essential that barriers to much-needed interventions are reduced for at-risk adolescents. In this article we review the legal and policy framework in South Africa for adolescent access to male circumcision. We are of the view that the framework does confer protection for adolescent boys while enabling access to male circumcision; however, we identify ambiguities and tensions that exist between the Children's Act, regulations and national guidelines. We recommend reform to further enable access by this vulnerable group to this prevention modality.

S Afr Med J 2016;106(12):1173-1176. DOI:10.7196/SAMJ.2016.v106i12.11215

There are many valid religious, cultural and public-health benefits to male circumcision. In South Africa (SA), it is often practised for religious reasons (generally performed shortly after the birth of a baby boy) or as part of cultural initiation practices (adolescent boys). Recently, there has been increased attention to male circumcision for another purpose, that of reducing the risk of HIV infection. ${ }^{[1,2]}$ Clinical trials have demonstrated that male circumcision is an effective strategy to reduce the risk of HIV transmission from HIVpositive women to uninfected men. ${ }^{[1,2]}$ Male circumcision is a key component of SA's national strategic plan. ${ }^{[3]}$

Many parents or legal guardians may elect to have boys in their care circumcised, and older boys themselves may wish to be circumcised; however, some human rights concerns have been raised regarding the practice. Firstly, how can children be protected from possible adverse consequences, such as botched cultural circumcisions? ${ }^{[4]}$ Secondly, how can the bodily integrity and autonomy rights of young boys be promoted, given that their parents or legal guardians may make the decision on their behalf in many instances? Thirdly, how can the involvement of older children in such decisions be facilitated where this is appropriate? ?[ $^{[3]}$

Male circumcision of boys under 18 years is regulated by the Children's Act (No. 58 of 2005) - hereafter referred to as the Act. ${ }^{[6]}$ The procedures that should be followed to implement these provisions are detailed in the General Regulations Regarding Children of 2010 (hereafter referred to as the Regulations). ${ }^{[7]}$ This creates a protective, normative framework for when and how circumcisions may take place involving boys under $18 .{ }^{[6]}$ The legislative framework is to be read with the National Department of Health $(\mathrm{NDoH})$ 's national guidelines, which address medical male circumcision performed under local anaesthetic. ${ }^{[8]}$ A critical question is whether and to what extent this legal and policy framework facilitates medical male circumcisions of adolescent boys. This article describes the legal and policy framework, and critically reviews the approach it takes. It concludes with recommendations for law and policy reform to ensure better access to this valuable HIV-prevention tool for this at-risk group.

\section{Legal and policy framework for medical malle circumcision of boys under 18}

The Act deals expressly with male circumcision of boys under 18 by providing when and how it may take place. ${ }^{[6]}$ There are several protections for all male children, as well as some additional restrictions for boys under 16 who have less legal capacity. ${ }^{[6]}$ The Act's approach is guided by two broad principles: (i) that 'every child has the right not to be subjected to social, cultural and religious practices that are detrimental to his/her well-being ${ }^{[6]}$ (this includes the right, in certain circumstances, to choose not to be circumcised); ${ }^{[6]}$ and (ii) that a child, depending on his/her age, maturity and stage of development, has the right to participate in any matter concerning him/her. ${ }^{\left[{ }^{[]}\right.}$

\section{Circumcision of boys over 16 but under 18 years of age Reason}

The Act allows 16- and 17-year-old boys to be circumcised for any reason provided several requirements are met.

\section{Consent}

The Act requires that a 16- or 17-year-old boy must have consented (in the prescribed manner) to his own circumcision. ${ }^{[6]}$ The boy has the right to refuse to be circumcised. ${ }^{[6]}$ This clearly indicates that the drafters of the Act intended boys of 16 and over to be able to consent independently to a circumcision, regardless of the method used. For circumcision for cultural reasons, this consent should be documented using a form supplied in the Regulations. ${ }^{[9]}$ If the circumcision is being done for another reason, there is no official form that must be used to record the consent. We hold this to mean that, generally, there is no requirement in the Act for parental involvement in the circumcision of boys aged 16 and $17 .^{[10,11]}$

However, if the circumcision is being done for social-cultural reasons, or for medical reasons and is being performed under local anaesthetic, then the Regulations and the national guidelines, 
respectively, introduce parental involvement. More specifically, where circumcision is being done for social or cultural reasons, Form 2 of the Regulations provides that the parent or legal guardian should sign the circumcision consent form to confirm that they have 'assisted' the child in making the decision, and that the boy is over 16 and has capacity to understand the risks and benefits of the procedure. More specifically, where circumcision is being done for medical reasons and is being performed under local anaesthetic, the $\mathrm{NDoH}$ guidelines do not clearly state that over-16s can provide self-consent (without parental involvement) ${ }^{[8]}$ and the rationale given in the guidelines about the consent approach seems anchored in consent for treatment or, alternatively, consent for surgery at various places in the document, which is confusing for those trying to apply the guidelines.

\section{Counselling}

The Act requires that 16- or 17-year-old boys must have been given 'proper' counselling. ${ }^{[6]}$ The Regulations provide that if the circumcision is for social or cultural reasons, then the counselling should be provided by a parent, legal guardian or a person providing social services. ${ }^{[7]}$

\section{Prescribed manner}

The Act requires that 16 - or 17 -year-olds must be circumcised in the manner prescribed. ${ }^{[6]}$ The Regulations only set out norms for procedures to be followed for social or cultural circumcision, ${ }^{[7]}$ namely that it must be performed in accordance with the accepted cultural practices of that boy. ${ }^{[7]}$ Furthermore, it must be done by a medical practitioner or person with knowledge of the social or cultural practice, who is properly trained to conduct such circumcisions. ${ }^{[7]}$ The national guidelines also detail the procedures and equipment that should be used for a medical circumcision. ${ }^{[8]}$ For a social or cultural circumcision, the person performing the procedure must use the prescribed equipment, including sterilisation and universal infection control procedures. ${ }^{[7]}$

Table 1 outlines the existing norms. If we apply these norms to the issue of 16- and 17-year-old boys wishing to access medical male circumcision for HIV prevention, there is no potential 'reason' barrier because any reason for circumcision is acceptable. However, there is potential conflict about the consent process because the Act has a self-consent approach that allows 16- and 17-year-old boys to consent independently, whereas the national guidelines for medical circumcision involving local anaesthetic appear to introduce parental involvement in the decisions of 16- and 17-year-olds. We argue that the Act should prevail over the policy.

Boys must receive counselling before the circumcision. The Act requires 'proper' counselling but no detail is provided on who should provide this service or its content. Nevertheless, there is some practical guidance in the national guidelines on the purpose and the issues that should be raised during counselling. ${ }^{[8]}$ These include helping clients to identify their HIV risk, exploring the benefits of knowing one's HIV status and ensuring they know circumcision may not provide full protection against HIV acquisition; ${ }^{[8]}$ therefore, persons involved in offering male circumcision for HIV prevention should include these topics in counselling.

\section{The circumcision of boys under 16 years \\ Reason}

The Act prohibits male circumcision of boys under 16 unless it can be shown that the circumcision will be performed for 'religious' purposes or 'medical' reasons. ${ }^{[6]}$ The Act does not expressly refer to, or define, cultural circumcisions ${ }^{[12]}$ (even though the former provisions are all under the sub-heading of 'social, cultural and religious practices'). This omission implies that boys should only be circumcised for a cultural reason when they reach the age of $16 .^{[13]}$

\section{The circumcision of boys under 16 for 'religious purposes' Reason}

The Act does not define the term 'religious purposes', yet it provides that such circumcisions be carried out in accordance with the practices of that religion. ${ }^{[6]}$ The Regulations state further that such a circumcision must be part of the doctrines of that religion. ${ }^{[7]}$ Neither the Act nor the Regulations define the term 'religious doctrine' but dictionary definitions are available..$^{[12]}$

\section{Consent}

The Regulations (in 6(3)) provide further that religious circumcision with under-16s must be undertaken with the consent of both parents or guardians, and documented on Form 3 of the Regulations.

\section{Other}

In addition, such circumcisions must be performed by a medical practitioner or a person from that religion, who has been trained to perform such circumcisions, and carried out using the prescribed equipment, sterilisation and universal infection-control procedures. ${ }^{[7]}$

\section{The circumcision of boys under $\mathbf{1 6}$ for 'medical reasons' Reason}

The Act does not define the term 'medical reasons' but it is assumed that the rationale is to address either an immediate health condition such as a urinary tract infection, ${ }^{[8]}$ or a condition the child may be at risk for in the future, such as HIV infection, other sexually transmitted infections, genital cancers and balanitis. ${ }^{[1,8]}$

Table 1. Existing norms for male circumcision of 16- and 17-year-old boys

\begin{tabular}{|c|c|c|c|}
\hline Reason & Consent to be provided by & $\begin{array}{l}\text { Procedure } \\
\text { performed by }\end{array}$ & Requirements for the procedure \\
\hline Any reason & $\begin{array}{l}\text { Boy himself (age } 16-17)\left(\mathrm{CA}^{[6]}\right) \text {; and } \\
\text { documented on Form } 2\left(\text { Regulations }{ }^{[9]}\right)\end{array}$ & $\begin{array}{l}\text { Not prescribed } \\
\left.\text { (Regulations }^{[7]}\right)\end{array}$ & $\begin{array}{l}\text { Not prescribed } \\
\left.\text { (Regulations }^{[7]}\right)\end{array}$ \\
\hline Social or cultural practice & $\begin{array}{l}\text { Boy himself (age } 16-17)\left(\mathrm{CA}^{[6]}\right) \text {; 'assisted' } \\
\text { by parent or guardian and documented on } \\
\left.\text { Form } 2 \text { (Regulations }{ }^{[9]}\right)\end{array}$ & $\begin{array}{l}\text { Trained practitioner } \\
\text { (Regulations }^{[7]} \text { ) }\end{array}$ & $\begin{array}{l}\text { Prescribed equipment } \\
\text { (Regulations }^{[7]} \text { ) }\end{array}$ \\
\hline Medical & $\begin{array}{l}\text { Boy himself (age } 16-17)\left(\mathrm{CA}^{[6]}\right) \text {; parent or } \\
\text { legal guardian if regarded as surgery }(\mathrm{NDoH} \\
\left.\text { guidelines }^{[8]}\right)\end{array}$ & $\begin{array}{l}\text { Medical practitioner } \\
\left(\mathrm{NDoH} \text { guidelines }{ }^{[8]}\right)\end{array}$ & Detail (NDoH guidelines ${ }^{[8]}$ ) \\
\hline
\end{tabular}




\section{Consent}

The Act does not specifically state who should provide consent for circumcisions of boys under 16 when they are done for medical reasons. ${ }^{[13]}$ The Regulations also do not give any further details on this issue, or provide any accompanying form to be completed to document the consent process. This creates some ambiguity. However, we submit that useful guidance is implied in the Act, which provides that over-16s provide independent consent, therefore implying that under-16s need proxy consent. ${ }^{[14]}$ Furthermore, the medical procedure used could provide some direction on the consent norms. If circumcision is considered an invasive surgical procedure performed under local anaesthetic, i.e. an 'operation' (as in fact it is defined by the national guidelines ${ }^{[8]}$ ), then the norms in the Act would be that the 'assistance' of a parent or legal guardian is required in addition to the consent of persons from the age of $12 . .^{[6,13]}$

\section{Other}

'Medical' circumcisions must be done on the recommendation of a medical practitioner. ${ }^{[6]}$ The Regulations do not detail how such medical circumcisions should be done, but this is detailed in the $\mathrm{NDoH}$ guidelines. ${ }^{[8]}$

Table 2 summarises the norms for circumcision of boys under 16. If we apply these norms to the issue of under-16-year-old boys wishing to access medical male circumcision for HIV prevention, it is important to recognise that adolescents should ideally have access to HIV-prevention tools before sexual debut, which makes younger adolescents a key subsample for accessing circumcision. We argue that HIV prevention is a valid medical reason for a circumcision. Other commentators have also asserted that the term 'medical reasons' is broad enough to include HIV prevention. ${ }^{[15]}$ In contrast, McQuoid-Mason ${ }^{[16]}$ has argued that a circumcision has to be for a current medical reason and not a possible future one. We recommend following Vawda and Maqutu's ${ }^{[15]}$ approach because, given the severity of the HIV epidemic and the HIV risk adolescents face, taking steps to minimise such risk is a critical health issue. ${ }^{[13]}$ If circumcision is to be offered to boys under 16 as part of HIVprevention strategies, then the health reason for the circumcision should be documented, i.e. to lower their current or future risk of HIV infection. A parent or guardian should give permission for medical circumcisions for boys under 16, as implied by the Act. National guidelines could be consulted for the form to be used. National guidelines should be consulted for how to implement the procedure.

\section{Conclusions}

There is a protective framework for male circumcision of adolescent boys. There are more restrictions on 'religious' and 'cultural' circumcisions for boy children than on 'medical' circumcisions, perhaps because the former are done at birth when child participation principles cannot be applied, and the latter because of the adverse consequences observed each year. ${ }^{[4]}$

However, tensions and ambiguities remain in this protective framework. Roll-out of medical male circumcision may be even further facilitated if these were addressed. We recommend some reforms to strengthen the framework to facilitate access by at-risk adolescents in SA to this one component of a comprehensive portfolio of HIV-prevention options.

\section{Regarding consent}

HIV-prevention providers trying to ensure access for boys aged 16 and 17 may experience confusion about whether to seek consent from the adolescent alone, or to seek involvement from a parent as well. This is because the Act implies self-consent and the national guidelines imply parental involvement. Adopting a parental consent approach may deter some 16- and 17-year-olds from seeking this prevention service. The national guidelines should be revised to be much clearer about the consent approach, and should mirror the consent approach implied in the Children's Act (i.e. self-consent at 16, parental consent for under-16s). Also, HIV-prevention providers trying to ensure access for boys aged 12 - 15 may be uncertain of the consent procedures. For under-16s, the Act or Regulations should spell out which adults are required to consent for health-related circumcisions, and include a form designed to document this.

\section{Regarding reasons}

All HIV-prevention providers may breathe more easily if it were understood that HIV prevention is a legitimate health reason for male circumcision. ${ }^{[13]}$ Also, we recommend that the Regulations should specify the minimum standards that should be followed in the procedure so as to ensure that medical circumcisions are treated equally to those done for religious or cultural reasons. ${ }^{[13]}$ The Regulations should also include a form specifically designed to document consent to circumcision for a health reason. Lastly, we recommend that the national guidelines ${ }^{[8]}$ should provide that HIV prevention is a valid medical reason for circumcision of boys under $166^{[13]}$

With 2.1 million adolescents infected with HIV globally, ${ }^{[17]}$ and adolescents showing some of the highest incidence rates in the world, ${ }^{[18]}$ it is essential that any barriers hindering access to prevention modalities be addressed - including possible legal/policy barriers. In SA, we hope that amendments to the legal and policy framework could further expand access by this much-affected group to a muchneeded intervention in the form of male circumcision.

Table 2. Existing norms for male circumcision of boys under 16 years of age

\begin{tabular}{|c|c|c|c|}
\hline Reason & Consent to be provided by & $\begin{array}{l}\text { Procedure performed } \\
\text { by }\end{array}$ & $\begin{array}{l}\text { Requirements for the } \\
\text { procedure }\end{array}$ \\
\hline $\begin{array}{l}\text { Religious purposes as it is part } \\
\text { of the religious doctrines of that } \\
\text { religion }\left(\mathrm{CA}^{[6]}\right)\end{array}$ & 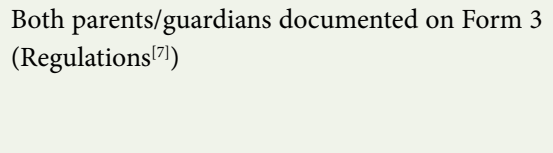 & $\begin{array}{l}\text { Medical practitioner } \\
\text { or trained person } \\
\text { from that religion } \\
\left(\text { Regulations }{ }^{[7]}\right)\end{array}$ & $\begin{array}{l}\text { Using prescribed equipment } \\
\text { (Regulations }^{[7]} \text { ) }\end{array}$ \\
\hline Medical reasons $\left(\mathrm{CA}^{[6]}\right)$ & $\begin{array}{l}\text { A parent/ guardian (implied by } \mathrm{CA}^{[6]} \text { ) 'With } \\
\text { the assistance of a parent/guardian and with } \\
\text { the consent of a boy child himself if over } 12 \\
\text { (alternatively with the consent of the parent/ } \\
\text { guardian if under 12) } \\
\text { (applying norms of the CA for 'operations') }\end{array}$ & $\begin{array}{l}\text { Specified } \\
\left(\mathrm{NDoH} \text { guidelines }{ }^{[8]}\right)\end{array}$ & $\begin{array}{l}\text { Specified (NDoH } \\
\text { guidelines }^{[8]} \text { ) }\end{array}$ \\
\hline Any other reason $\left(\mathrm{CA}^{[6]}\right)$ & Circumcision is prohibited $\left(\mathrm{CA}^{[6]}\right)$ & Procedure is prohibited & Procedure is prohibited \\
\hline
\end{tabular}


Acknowledgements. This article was made possible by funding from award number 1RO1 A1094586 from the National Institutes of Health (NIH) entitled CHAMPS (Choices for Adolescent Methods of Prevention in South Africa). The content is solely the responsibility of the authors and does not necessarily represent the official views of the $\mathrm{NIH}$, or the views of any council or committee with which the authors are affiliated. Many thanks also to Mr Amin Matola for assistance with referencing and formatting.

1. Auvert B, Taljaard D, Lagarde E, et al. Correction: Randomized, Controlled Intervention Trial of Male Circumcision for Reduction of HIV Infection Risk: The ANRS 1265 Trial. PLoS Med 2006;3(5):e226 http://dx.doi.org/10.1371/journal.pmed.0030226

2. Weiss HA, Quigley MA, Hayes RJ. Male circumcision and risk of HIV infection in sub-Saharan Africa: A systematic review and meta-analysis. AIDS 2000;14(15):2361-2370.

3. National Department of Health, South Africa National Strategic Plan on HIV, STIs and TB 2012 - 2016. Pretoria: NDoH $\quad$ http.//www govza/documents/national-strategic-plan-hiv-stis-and-tb-2012-2016 (accessed 29 February 2016).

4. Child Rights International Network (CRIN). South Africa: Clamping down on botched

4. Child Rights International Network (CRIN). South Africa: Clamping down on botched
circumcisions, 2007. https://wwww.rin.org/en/library/news-archive/south-africa-clamping-downbotched-circumcisions (accessed 21 December 2015).

5. Svoboda JS. Circumcision of male infants as a human rights violation. J Med Ethics 2013;39(7):469474. http://dx.doi.org/10.1136/medethics-2012-101229

6. South Africa. Children's Act No. 38 of 2005. Government Gazette No. 28944, 2005. http://www.plusto. com/uploads/5780/docs/Childrens-Act.pdf (accessed 29 February 2016)

7. South Africa. Children's Act No. 38 of 2005. Regulations: General Regulations Regarding Children Pretoria: Government Gazette No. 33076, Notice No. 261, 2010
8. National Department of Health, South Africa. South African National Guidelines for Medical Male Circumcision under Local Anaesthesia (2010). Pretoria: NDoH, 2010.

9. South Africa. Children's Act No. 38 of 2005. Regulations: General Regulations Regarding Children. Form 2. Pretoria: Government Gazette No. 33076, Notice No. 261, 2010.

10. Strode A, Slack C, Essack Z. Child consent in South African law: Implications for researchers, service providers and policy-makers. S Afr Med J 2010;100(4):247-249.

providers and policy-makers. S Afr Med J 2010;100(4):247-249.
11. Strode A, Slack C, Essack Z. Child consent in South African law: Implications for researchers, service providers and policy-makers (Letter to the Editor). S Afr Med J 2011;101(9):604-606.
prodich

12. The Free Dictionary - Medical Dictionary. http://medical-dictionary.thefreedictionary.com/ medical+treatment (accessed 21 December 2015)

13. University of Washington. Department of Global Health. AIDS Law Brief Background Paper: Age of Consent to Voluntary Male Medical Circumcision in South Africa. June 2015. Seattle: University of Washington, 2015.

14. Strode A, Slack C. Child research in South Africa: How do the new regulations help? S Afr Med J 2015;105(11):899-900. http://dx.doi.org/10.7196/SAMJ.2015.V105I11.9838

15. Vawda YA, Maqutu LN. Neonatal circumcision - violation of children's rights or public health necessity? S Afr J Bioethics Law 2011;4(1):36-41.

16. McQuoid-Mason DJ. Is the mass circumcision drive in KwaZulu-Natal involving neonates and children less than 16 years of age legal? What should doctors do? S Afr Med J 2013;103(5):283-284. http://dx.doi.org/10.7196/SAMJ.6701

17. World Health Organization. Maternal, newborn, child and adolescent health: Adolescent development. Geneva: WHO, 2016. http://www.who.int/maternal_child_adolescent/topics/adolescence/dev/en Geneva: WHO, 2016.

18. Bekker L-G, Gill K, Wallace M. Pre-exposure prophylaxis for South African adolescents: What evidence? S Afr Med J 2015;105(11):907-911. http://dx.doi.org/10.7196/SAMJ.2015.v105i11.10222

Accepted 19 October 2016 